\title{
Anthropometric, physical function and general health markers of Masters athletes: a cross-sectional study
}

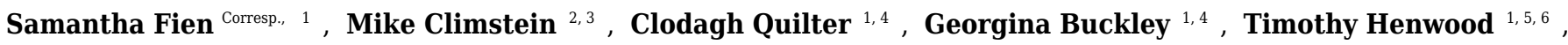 \\ Josie Grigg ${ }^{1}$, Justin W. L. Keogh ${ }^{1,7,8}$ \\ ${ }^{1}$ Health Science and Medicine, Bond University, Robina, Queensland, Australia \\ 2 Water Based Research Unit, Faculty of Health Sciences, Bond University, Robina, Queensland, Australia \\ 3 Exercise Health \& Performance Faculty Research Group, The University of Sydney, Lidcombe, New South Wales, Australia \\ 4 Physical Education and Sport Sciences, University of Limerick, Dublin, Ireland \\ 5 School of Human Movement and Nutritional Science, University of Queensland, Brisbane, Queensland, Australia \\ 6 Community Wellness and Lifestyle, Southern Cross Care (SA \& NT) Inc., Adelaide, South Australia, Australia \\ 7 Human Potential Centre, Auckland University of Technology, Auckland, New Zealand \\ 8 Cluster for Health Improvement, Faculty of Science, Health, Education and Engineering, University of the Sunshine Coast, Sunshine Coast, Queensland, \\ Australia
}

Corresponding Author: Samantha Fien

Email address: samantha.fien@student.bond.edu.au

Once the general decline in muscle mass, muscle strength and physical performance falls below specific thresholds, the middle aged or older adult will be diagnosed as having sarcopenia (a loss of skeletal muscle mass and strength). Sarcopenia contributes to a range of adverse events in older age including disability, hospitalisation, institutionalisation and falls. One potentially relevant but understudied population for sarcopenia researchers would be Masters athletes. Masters sport is becoming more common as it allows athletes (typically 40 years and older) the opportunity to participate in individual and/or team sports against individuals of similar age. This study examined a variety of measures of anthropometric, physical function and general health markers in the male and female Masters athletes who competed at the 2014 Pan Pacific Masters Games held on the Gold Coast, Australia. Bioelectric impedance analysis was used to collect body fat percentage, fat mass and fat-free mass; with body mass, height, body mass index (BMI) and sarcopenic status also recorded. Physical function was quantified by handgrip strength and habitual walking speed; with general health described by the number of chronic diseases and prescribed medications. Between group analyses utilised ANOVA and Tukey's post-hoc tests to examine the effect of age group (40-49, 50-59, 60-69 and $>70$ years old) on the outcome measures for the entire sample as well as the male and female subgroups. A total of 156 athletes (78 male, 78 female; mean 55.7 years) provided informed consent to participate in this study. These athletes possessed substantially better anthropometric, physical function and general health characteristics than the literature for their less physically active age-matched peers. No Masters athletes were categorised as 
being sarcopenic, although one participant had below normal physical performance and six participants had below normal muscle strength. In contrast, significant age-related reductions in handgrip strength and increases in the number of chronic diseases and prescribed medications were observed for the overall cohort as well as the male and female sub-groups. Nevertheless, even those aged over 70 years only averaged one chronic disease and one prescribed medication. These results may suggest that participation in Masters sport helps to maintain anthropometry, physical function and general health in middle-aged and older adults. However, it is also possible that only healthier middle-aged and older adults with favourable body composition and physical function may be able to participate in Masters sport. Future research should therefore utilise longitudinal research designs to determine the health and functional benefits of Master sports participation for middle-aged and older adults. 
1 Anthropometric, physical function and general health markers of Masters athletes: a cross-

2

3 Samantha Fien ${ }^{1}$, Mike Climstein ${ }^{2,3}$, Clodagh Quilter ${ }^{1,4}$, Georgina Buckley ${ }^{1,4}$, Tim Henwood

$4 \quad 5,6,1$, Josie Grigg ${ }^{1}$, Justin WL Keogh ${ }^{1,6,7}$

5

$6{ }^{1}$ Health Science and Medicine, Bond University, Robina, Queensland, Australia

$7{ }^{2}$ Water Based Research Unit, Faculty of Health Sciences, Bond University, Robina, Queensland, 8 Australia

$9{ }^{3}$ Exercise Health \& Performance Faculty Research Group, Faculty of Health Sciences, The 10 University of Sydney, Lidcombe, New South Wales, Australia

$11{ }^{4}$ Physical Education and Sport Sciences, University of Limerick, Limerick, Ireland

${ }^{5}$ School of Human Movement and Nutritional Science, University of Queensland, Brisbane,

Queensland, Australia

14

${ }^{6}$ Community Wellness and Lifestyle, Southern Cross Care (SA \& NT) Inc., Adelaide, South Australia, Australia

${ }^{7}$ Human Potential Centre, AUT University, Auckland, New Zealand

$17{ }^{8}$ Cluster for Health Improvement, Faculty of Science, Health, Education and Engineering,

18 University of the Sunshine Coast, Sunshine Coast, Queensland, Australia

\section{sectional study}


20 Corresponding Author: Samantha Fien

21 Faculty of Health Sciences,

22 Bond University

2314 University Drive, Robina, QLD, AUSTRALIA 4226

24 Phone: 0402479015 Fax: +61 755954480

25 Samantha.fien@student.bond.edu.au 


\title{
Anthropometric, physical function and general health markers of Masters athletes: a cross-
}

\author{
sectional study
}

\section{ABSTRACT}

Once the general decline in muscle mass, muscle strength and physical performance falls below specific thresholds, the middle aged or older adult will be diagnosed as having sarcopenia (a loss of skeletal muscle mass and strength). Sarcopenia contributes to a range of adverse events in older age including disability, hospitalisation, institutionalisation and falls. The European Working Group on Sarcopenia for Older People (EWGSOP) framework is commonly used to better understand factors contributing to sarcopenia and interventions, which may minimise its negative effects. One potentially relevant but understudied population for sarcopenia researchers would be Masters athletes. Masters sport is becoming more common as it allows athletes (typically 40 years and older) the opportunity to participate in individual and/or team sports against individuals of similar age. This study examined a variety of measures of anthropometric, physical function and general health markers in the male and female Masters athletes who competed at the 2014 Pan Pacific Masters Games held on the Gold Coast, Australia. Bioelectric impedance analysis (Avery et al.) was used to collect body fat percentage, fat mass and fat-free mass; with body mass, height, body mass index (BMI) and sarcopenic status also recorded. Physical function was quantified by handgrip strength and habitual walking speed; with general health described by the number of chronic diseases and prescribed medications. Between group analyses utilised ANOVA and Tukey's post-hoc tests to examine the effect of age group (40-49, 50-59, 60-69 and $>70$ years old) on the outcome measures for the entire sample as well as the 
48 male and female sub-groups. A total of 156 athletes (78 male, 78 female; mean 55.7 years)

49 provided informed consent to participate in this study. These athletes possessed substantially

50 better anthropometric, physical function and general health characteristics than the literature for

51 their less physically active age-matched peers. No

52 Masters athletes were categorised as being sarcopenic, although one participant had below

53 normal physical performance and six participants had below normal muscle strength. In contrast,

54 significant age-related reductions in handgrip strength and increases in the number of chronic

55 diseases and prescribed medications were observed for the overall cohort as well as the male and

56 female sub-groups. Nevertheless, even those aged over 70 years only averaged one chronic

57 disease and one prescribed medication. These results may suggest that participation in Masters

58 sport helps to maintain anthropometry, physical function and general health in middle-aged and

59 older adults. However, it is also possible that only healthier middle-aged and older adults with

60 favourable body composition and physical function may be able to participate in Masters sport.

61 Future research should therefore utilise longitudinal research designs to determine the health and

62 functional benefits of Master sports participation for middle-aged and older adults.

63

64

\section{INTRODUCTION}

The field of gerontological research has sought to characterize the rate of age-related decline in physical function and overall health and wellness. For example, it has been found that in sedentary individuals $\mathrm{VO}_{2}$ max decreases by $10 \%$ per decade after the age of 30 years (Lepers, 2016 \#405). The ageing process is also commonly associated with declines in muscle mass and strength that subsequently lead to functional declines, physical disability and falls (Wroblewski et al. 2011). This age-related decline in muscle mass and physical function is termed sarcopenia. According to the European Working Group for Sarcopenia in Older People (EWGSOP), 
72 sarcopenia has been defined as 'the loss of skeletal muscle mass and strength that occurs with

73 advanced aging' and represents a diminished state of health (Cruz-Jentoft et al. 2010a). The

74 diagnosis of sarcopenia is based upon an individual's muscle mass, muscular strength and

75 physical performance. While the EWGSOP endorsed a variety of assessments of muscle mass,

76 strength and physical performance, Bioelectric impedance analysis (Avery et al.), handgrip

77 strength and gait speed are valid assessments that are commonly used during field based testing

78 (Cruz-Jentoft et al. 2010b).

A recent systematic review of studies using the EWGSOP sarcopenia diagnostic criteria has demonstrated sarcopenia prevalence rates of $1-29 \%$ in community dwelling adults over the age of 50 years, $14-33 \%$ in older adults in long-term care and $10 \%$ in acute hospital-care older populations (Cruz-Jentoft et al. 2014). Such results suggest that the rate of sarcopenia increases with age and the degree of aged care, with data from our group reporting sarcopenia prevalence rates of $\sim 40 \%$ in Australian aged care settings (Senior et al. 2015). It is perhaps even more alarming that residential aged care facilities may have up to $85 \%$ of residents below normal thresholds for muscle strength and 97\% below the threshold for physical performance (Keogh et al. 2015). The increased prevalence of sarcopenic handgrip strength and gait speed is consistent with the study of 415 older adults between the age of $60-99$ years, in which the age-related decline in handgrip strength and gait speed was greater than for muscle mass (Bai et al. 2016). There is also a general age-related increase in the number of chronic diseases and prescribed medications, with these again often being greater in residential aged care than community dwelling older adults. Specifically, Australian residential aged care adults have been reported to have an average of 14-15 chronic diseases and 11-15 prescribed medications (Fien et al. 2016; Keogh et al. 2015). 
95

96

97

98

99

100

101

102

103

104

105

106

107

108

109

110

111

112

113

114

115

116

117

One segment of the middle-aged and older community dwelling community that would appear of interest to sarcopenia researchers are Masters athletes (McKean et al. 2006; Pantoja et al. 2016;

Ransdell et al. 2009; Wroblewski et al. 2011). Masters athletes are typically individuals aged 40 years or older who systematically train and compete in one or more individual or team sports (Lepers \& Stapley 2016). With an ageing of the population and the growing interest in prolonging health and wellbeing there has been a rise in the number of Masters athletes, with recent data for the New York marathon indicating that more than 50\% of the total male finishers and more than $40 \%$ of female finishers were Masters athletes (Lepers \& Stapley 2016). As some Master athletes may have extensive training backgrounds for many decades, they may be an ideal population for gerontological and sarcopenic research. Given their continued levels of sports and activity participation, it would be hypothesised that Masters athletes would have better health than their same aged, but less active peers. To this end, Masters athletes may allow researchers to better understand the true magnitude of the age-related decline in physical function (Geard et al. in press; Young et al. 2008).

Typically, studies of Masters athletes demonstrate age-related decline in anthropometry, physical function and general health markers, but these declines are less pronounced and typically occur at an older age than in the wider population (Borges et al. 2016). For example, in a cross sectional study of 40 high level Masters athletes (20 males and 20 female, aged 40 to 81 years) who trained 4-5 times week, age was significantly positively correlated to body mass index (BMI) and body fat percentage (Wroblewski et al. 2011). When all 40 participants were pooled together, significant declines in quadriceps peak torque were only observed for the participants 60 years and older (Wroblewski et al. 2011). Masters athletes are typically individuals aged 40 years or older who systematically train and compete in one or more individual or team sports 
118 (Lepers, 2016 \#405). The qualifying age of masters athletes depends upon the sport and may also

119 be dependent upon the specific distance of that sport. For example, the USA Track and Field

120 association defines a MA as 30 years of age however for longer distances, 40 years of age". The

121 major results of this study was that 30-35 and 35-45 year old groups were not significantly

122 different across any of the anaerobic parameters; with significant decrements only being

123 observed in those aged over 45 years. It was also observed that the age-related decline in

124 muscular power $(26-32 \%)$ for athletes 45 years and older was greater as compared to the

125 decline seen in muscular strength $(16-23 \%)$ or velocity $(13-14 \%)$. Body mass index has also

126 been used as an indicator of general health in several studies of Masters athletes (Climstein et al.

127 in press; Walsh et al. 2011; Walsh et al. 2013b). The largest of these studies examined the BMI

128 of 6,071 master's athletes (51.9\% male and $48.1 \%$ female) aged 25 to 91 years of age competing

129 in the Sydney World Masters Games in 2009 (Walsh et al. 2011). While a significant positive

130 correlation was found between age and BMI, Masters athletes demonstrated significantly lower

131 BMI than age-matched controls (Walsh et al. 2011).

132 While a number of studies have described the BMI and performance of Masters athletes, little is

133 known about Masters Athletes wider anthropometric, functional and general health

134 characteristics; how these factors may change with ageing and how they compare to age-

135 matched, community dwelling controls. The aims of this cross-sectional study were to: 1)

136 characterize the body composition, muscle strength, physical function, number of chronic

137 diseases and medications in Masters athletes; and 2) gain some insight into how these factors

138 might be influenced by the age and sex of the Masters athletes. It was hypothesized that; 1)

139 Masters athletes across multiple age groups will exhibit high levels of muscle mass, handgrip

140 strength, gait speed and lower levels of chronic disease and prescribed medication usage; and 2) 
141 these outcomes will be significantly greater in male than female and younger rather than older

142 Masters athletes. Masters athletes in this context may provide a suitable research model to look

143 at the true physiological changes associated with age.

\section{METHODS}

\section{Study design}

146 This research utilized cross-sectional observational study design to characterize the body

147 composition, muscle strength, physical function and overall health and a number of health

148 related indicies of Masters athletes competing at the 2014 Pan Pacific Masters Games, Gold

149 Coast, Australia. This study received approval by the Bond University Human Research Ethics

150 Committee (RO1823) in accordance with the ethical standards of the Helsinki Declaration of

1511975 (revised in 2008).

152 Participants were recruited at the Masters Pan Pacific Games whereby participants had to go to 153 registration desk at the Gold Coast Convention Centre and there were a number of stalls in 154 relation to health, nutrition and physical activity. We had a selected area whereby participants 155 could partake if they wanted to.

\section{Sample}

157 Eligible participants for this study included all competitors (national and international) who were participating in at least one sport (out of 43 sports available at the 2014 Pan Pacific Masters

159 Games. Following attainment of informed consent (verbal and written) to participate all 160 participants initially completed a brief questionnaire, which included basic demographics (age, 161 sport(s), and training time) and a medical health history questionnaire (chronic disease(s) and 
162 prescribed medications).

163

164

165

166

167

168

169

170

171

172

173

174

175

176

177

178

179

180 181 Cruz-Jentoft et al. (2010).

\section{Anthropometry}

Height was assessed using a stadiometer to an accuracy of $0.5 \mathrm{~cm}$. Body mass and body composition was assessed using a Tanita BIA body composition analyzer (Model MC-980MA, Illinois, USA) (Kelly \& Metcalfe 2012). The BIA analyzer was calibrated each morning prior to any assessments. Participants were to have avoided strenuous exercise for the previous 24 hours, bladder void and be hydrated prior to body composition assessment. The subjects were instructed to remove footwear, step onto the BIA machine and follow the directions of the machine whilst holding the electrodes in each hand. The BIA uses an algorithm based on the relative electrical resistance in lean tissue, fat and water to calculate body composition measures. The Tanita uses four reference points in the body, hands and both feet and then produces a complete report of fat and muscle percentage. The Australian general population data was used (aged 35 years and older) available from the 2011-2012 Australian Bureau of Statistics Australian Health Survey were used for comparative purposes (Australian Bureau of Statistics 2012).

The anthropometric data collected allowed for each participant to be screened for sarcopenia according to EWGSOP guidelines (Cruz-Jentoft et al. 2010b). The EWGSOP screening algorithm consisted of assessing gait speed, handgrip strength and muscle mass (i.e., lean mass).

In order to be defined sarcopenic, individuals needed to have below normal levels of muscle mass and muscle strength or performance, using gender-specific cut-off points summarised by

\section{Handgrip strength}


183 Handgrip strength was assessed on the dominant hand using a hand-held dynamometer (Jamar 184 handgrip dynamometer, Sammons Preston Roylan, Bolingbrook, IL, USA). The dynamometer

185 handle grip width was individualized for each participant. Individuals performed the handgrip by

186 holding their preferred hand in front of the shoulder, with the elbow bent at a $90^{\circ}$ angle and

187 instructed to squeeze the dynamometer as hard as possible for three seconds. Two attempts were

188 allowed with the maximum force (kg's) recorded (Reijnierse et al. 2017). Participants were 189 allowed a brief rest period $(\sim 1 \mathrm{~min})$ between the two trials, with the maximum force produced 190 across the two attempts utilised for statistical purposes.

\section{Gait speed}

192 Gait speed was recorded using a computer interfaced electronic system (GaitMat II, EQInc;

193 Model GaitMat II, USA), which required participants to walk across a $3.66 \mathrm{~m}$ (11.91 ft.) long 194 pressure mat system (McDonough et al. 2001). Participants completed two trials at their habitual 195 gait speed in regular footwear. All participants were provided the following instructions: "Walk 196 towards the end of the room in the center of the mat at a pace that is comfortable for you". All 197 participants initiated from a standing start $2 \mathrm{~m}(6.56 \mathrm{ft}$.) from the gait analysis platform in order 198 to minimize the effects that either acceleration or deceleration may have on the outcome 199 measures (Kressig et al. 2004). Participants were permitted to have as much rest as was required 200 between measures, with rest times typically being up to one minute. The fastest of each 201 participant's two trials was kept for statistical analysis.

\section{Self-reported data}

203 Participants in this study were also asked a series of questions regarding their number of years 204 participating in Master sports, the number of hours training they would average in a typical 
205 training week as well as their number of chronic diseases and prescribed medications.

\section{Statistical analysis}

207 All data was initially inspected for normality by investigating kurtosis, skewness, Q-Q plots, as

208 well as the Kolmogorov-Smirnov test with the Lilliefors significance correction.

209 Heteroscedasticity was also assessed using Levene's test for the equality of variances. Overall

210 group data were presented as means and standard deviations for continuous measures and counts

211 (percentages) for categorical data. Between group comparisons were conducted on the basis of

212 sex (male and female) and age (40-49 years; 50-59 years; 60-69 years; or $\geq 70$ years) using one-

213 way ANOVA and Tukey post-hoc tests. As many significant sex-related differences were

214 observed and as there were some sex-related variation in the proportions of athletes across the

215 age groups, data is presented for the entire sample as well as for females and males separately. A

216 single sample t-test was performed to compare the height, mass and BMI of the Masters athletes

217 (sex combined) to Australian Bureau of Statistics (2012). All statistical analyses were performed

218 with SPSS (Ver. 22.0.0.0), with statistical significance for all analyses accepted at $\mathrm{p}<0.05$.

\section{RESULTS}

A total of 156 individuals ( 78 males (aged 40 to 86 years) and 78 females (aged 40 to 77 years)

Pan Pacific Master Games sports athletes volunteered to participate in this study. One hundred and forty-nine individuals competed in one sport at the Games, with the remaining seven competing in multiple sports. With regard to chronic diseases, a total of 40 participants $(25.4 \%$ of the overall sample) reported having one or more chronic diseases. Of these 40 participants, the most common chronic disease was hypertension $(n=22,55 \%)$ and diabetes mellitus $(n=14$, 
$22735 \%)$. Of the 40 participants who reported having at least one chronic disease, $(\mathrm{n}=18,11.6 \%)$

228 reported having two or more chronic diseases. A total of 121 participants $(77.6 \%$ of the overall

229 sample) reported having no prescribed medications. Of the 35 athletes who were on prescribed

230 medications, the most frequently prescribed number of medications was one $(\mathrm{n}=17,11 \%$ of the

231 overall sample). A total of 18 participants reported having two or more chronic diseases, most

232 commonly hypertension and dyslipidemia. The majority (77.6\%) of the Masters athletes had no

233 prescribed medications; with the majority of the remaining athletes $(\sim 11 \%)$ having one

234 medication. There was no difference between sex with regard to the number of athletes being

235 prescribed medications (males 16, females 19). The most commonly prescribed medications

236 were anti-hypertension (55\%) followed by oral hypoglycaemic agents $(35 \%)$.

237 The anthropometric, functional, training and health descriptors of the overall sample is provided

238 in Table 1. The only anthropometric variable where age-related differences were observed was

239 height, where the 50 to 59 year-old athletes were significantly taller than the 60 to 69 year-old

240 athletes $(p=0.003)$. From a functional perspective, there was a significant age-related decline in

241 handgrip strength $(\mathrm{p}=0.003)$ but no significant difference in habitual gait speed $(\mathrm{p}=0.673)$.

242 Based on our findings, Master athletes had a significant age-related increase in chronic diseases

$243(p=0.017)$ and prescribed medications $(p=0.015)$.

With regard to comparison to the Australian general population, as a group the Masters athletes were significantly taller $(+2.9 \%, \mathrm{p}<0.001)$, slightly lighter $(-2.7 \%)$ and a significantly lower BMI $(-8.5 \%, \mathrm{p}<0.001)$. Figure 1 provides a representation of the proportion of individuals defined as underweight, normal weight, overweight or obese by sample and sex. 
250 Due to their high level of lean muscle mass, no participants were described as being sarcopenic.

251 However, the number of participants who were identified as having handgrip muscle strength (n

$252=6)$ or physical performance outcomes $(n=1)$ below the sarcopenic cut-points (Cruz-Jentoft et 253 al. 2010b) are included in Figure 2.

255 The anthropometric, functional, training and health descriptors of the 78 male Masters athletes

256

257 are provided in Table 2. No significant age-related differences were observed for any

anthropometric variables. Inspection of the functional outcomes revealed a significant agerelated decline in handgrip strength $(\mathrm{p}<0.001)$ but no significant differences in habitual gait speed $(p=0.930)$. There was a significant age-related increase in chronic diseases $(p<0.001)$ and prescribed medications $(\mathrm{p}<0.001)$.

Please insert table 2 about here

The anthropometric, functional, training and health descriptors of the 78 female Masters athletes are provided in Table 3 . There were typically no significant age-related differences observed for any anthropometric variables. The only exception was height which was found to be significantly greater in the 50 to 59 year than 60 to 69 -year-old age group $(\mathrm{p}=0.003)$. Inspection of the functional outcomes revealed a significant age-related decline in handgrip strength $(p=0.003)$ but no significant differences in habitual gait speed $(p=0.673)$. There was a significant agerelated increase in chronic diseases $(p=0.017)$ and prescribed medications $(p=0.015)$.

Please insert table 3 about here 


\section{DISCUSSION}

271 The primary results of this study indicated that the male and female Masters athletes who

272 participated in this study possessed substantially better anthropometric, functional and health

273 characteristics than the generally less active Australian population their physically less active

274 age-matched peers. In 2011-12, adults spent an average of 33 minutes per day doing physical

275 activity, yet the distribution was highly skewed with $60 \%$ of adults doing less than 30 minutes,

276 and fewer than $20 \%$ doing an hour or more per day on average. In contrast, sedentary leisure

277 occupied just over 4 hours a day on average, with almost $30 \%$ of the adult population reporting

278 more than 5 hours of sedentary leisure activity each day. Our data indicated that when the

279 anthropometric, functional and health characteristics were compared for the Masters athletes

280 across the 10 year age groups, almost no significant age-related differences were observed. In

281 contrast, our data indicated significant age-related reductions in handgrip strength and increases

282 in the number of chronic disease and prescribed medications.

283 When compared to the Australian Bureau of Statistics (2012) BMI data, it was apparent that

284 Masters athletes had lower BMI which is suggestive of a healthier body composition. In

285 particular, while only $29 \%$ of the general population have a BMI indicative of underweight or

286 normal, approximately $49 \%$ of the Masters athletes were in these categories. Further, while

$287 \sim 32 \%$ of the Australian adult population was classified as obese $\left(\mathrm{BMI} \geq 30.0 \mathrm{~kg} / \mathrm{m}^{2}\right)$, only $\sim 13 \%$

288 of the Masters athletes were obese. Such results were consistent with previous research that

289 demonstrated that a high proportion of Masters athletes maintain a healthy BMI even into older

290 age (Climstein et al. in press; Walsh et al. 2011; Walsh et al. 2013b). As obesity is a well-

291 recognized risk factor for many chronic diseases including hypertension (resting blood pressure

$292 \geq 140 / 90 \mathrm{mmHg}$ ), cardiovascular disease, type 2 diabetes mellitus, obstructive sleep apnea and a 
293 number of cancers (Lavie et al. 2009; Pi-Sunyer 2009), based upon our findings, it appears that

294 long-term Masters sports participation results in a lower (improved) BMI and subsequently this

295 reduces their risk for many chronic diseases (Climstein et al. in press; McKean et al. 2006;

296 Pratley et al. 1995).

297 Subgroup analyses within the current study indicated that the differences in BMI and obesity

298 rates between the Masters athletes and the wider Australian population were more pronounced

299 for females than males. Specifically, $\sim 63 \%$ of the females compared to $\sim 35 \%$ male Masters

300 athletes were classified as being underweight or normal weight; with only $\sim 8 \%$ of female and

$30119 \%$ of male Masters athletes being obese. This tendency for the female Master athletes to report

302 lower BMI measures than male Master athletes in terms of their BMI and obesity rates appeared

303 consistent with Climstein and colleagues (in press) for the rates of chronic disease. Such results

304 may suggest that middle-aged and older females may obtain significantly greater body

305 composition and chronic disease benefits from participation in Masters sport than men of similar 306 age.

307 Another important aspect of maintaining health and function in ageing is the ability to maintain

308 muscle mass. None of the 114 Masters athletes aged 50 years and older (48 of who were 60 years

309 or older) in the current study were diagnosed as having sarcopenia, based upon the EWGSOP

310 criteria. Such prevalence rates for sarcopenia in the current study are substantially lower than the

$311 \quad 1-29 \%$ rates reported for community dwelling adults over the age of 50 years in a systematic

312 review (Cruz-Jentoft et al. 2014). Inspection of the other components of the sarcopenia diagnosis

313 (muscle strength and physical performance) indicated that only $3.8 \%$ of the participants were

314 below the sarcopenic handgrip strength cutpoints and $0.6 \%$ were below the sarcopenic gait speed

315 cutpoints. As $\sim 85 \%$ and $\sim 97 \%$ of Australian aged care residents may be below the sarcopenic 
316 handgrip strength and gait speed thresholds, respectively (Keogh et al. 2015), our data suggest

317 that Master athletes levels of muscular strength and physical function place them at very low risk

318 of adverse health events and entry into residential aged care (Abellan van Kan et al. 2009).

319 Results of the current study also indicated a very low prevalence of chronic diseases and

320 medications in the Masters athletes. Such a result was consistent with Climstein and colleagues

321 (in press) who observed a low rate of cardiovascular disease in Masters athletes. While the

322 current study observed a significant age-related increase in the number of chronic diseases and

323 prescribed medications, even those Masters athletes who were 70 years old or older only

324 reported an average of one chronic disease and one prescribed medication per individual. This

325

326

327

328

329

330

331

332

333

334

335

336

337

338

number of chronic diseases and medications was consistent with Climstein and colleagues (in press) and is substantially less than community dwelling older adults of similar age, especially those in residential aged care (Olsen 2016 ). This is exemplified by recent Australian data in which older adults living in residential aged care may average 14-15 chronic diseases and 11-15 prescribed medications per individual (Fien et al. 2016; Keogh et al. 2015).

The results of this current study and the remainder of the somewhat limited literature regarding Masters athletes strongly support the promotion of physical activity and sport across the lifespan. This promotion of a lifetime engagement in physical activity and sport may provide middle-aged and older individuals as well is the wider community a host of benefits. Physical activity and sport participation can have a variety of physiological benefits that reduce or even reverse the age-related declines in muscle mass, strength and performance (Fien et al. 2016; Kanamori et al. 2012). Sports participation also provides a range of social benefits (Kanamori et al. 2012), with this especially important for older adults who may experience declines in the size and quality of their social networks that accelerated when they retire from full-time employment (Julien et al. 
339 2013). From an economic perspective, older adults typically utilise a very high proportion of

340 most nations' health care expenditure due to the number of their chronic diseases, prescribed

341 medications and falls-related injuries (Manini \& Pahor 2009). Of particular concern is that the

$34220 \%$ of older adults who are no longer independent due to functional limitations have been

343 shown to account for $46 \%$ of the health care expenditure (Manini \& Pahor 2009). In absolute

344 terms, this represents a $\$ 5,000$ per year greater healthcare expenditure for each older adult with

345 functional limitations compared to those who have maintained their physical independence

346 (Manini \& Pahor 2009). Such savings in healthcare expenditure compared to dependent older

347 adults, may be even greater in Masters athletes than that reported for independent older adults.

348 Specifically, data from the present study indicating that the 48 Masters athletes over the age of

34960 years typically averaged only one chronic disease and one prescribed medication. This

350 contrasts with Australian data in which over half of Australian adults aged 65 years and older

351 have at least five chronic diseases (Australian Institute of Health and Welfare 2014).

352 The primary strength of the study was the sample size of 156 Masters athletes. While a few

353 studies of Masters athletes have had sample sizes that exceeded 400 participants (Climstein et al.

354 in press; Walsh et al. 2011; Walsh et al. 2013a; Walsh et al. 2013b), all of these studies with the

355 exception of Climstein and colleagues (in press) only collected BMI and used this to estimate

356 obesity rates. In comparison, Masters athlete studies that involved a greater number of outcome

357 measures or utilised more advanced data collection approaches have typically obtained much

358 smaller sample sizes $(n=6-40)$ than that used in our study (Gacesa 2017; Pantoja et al. 2016;

359 Power et al. 2016; Pratley et al. 1995; Wroblewski et al. 2011; Young et al. 2008).

360 The major limitation of this study was that the study was cross-sectional rather than longitudinal

361 in design. This meant that while age-related differences between the age groups could be 
362 described, true age-related changes that would be observed in individuals as they age could not

363 be quantified (Young et al. 2008). Nevertheless, the data did indicate the favorable

364 anthropometry, functional and health characteristics of the Masters athletes compared to data

365 reported for less physically active, age-matched individuals. There was also some imbalance in

366 the male and female ratios for 50-59 and 60-69 year old age groups which may have

367 contaminated the overall sample data. Age-related analyses for the 78 male and 78 female

368 Masters athletes were therefore performed separately in addition to data presented for the overall

369 cohort of 156 athletes. It is also unclear how the athletes who participated in the study may differ

370 to the athletes who did not participate in the study and if there was any recruitment bias whereby

371 the more functional and healthy Masters athletes would be more likely to participate than their

372 less functional or healthy peers.

373

374 CONCLUSIONS

375 The results of this study indicate that Masters athletes possess more favourable anthropometric,

376 functional and health characteristics than the age-matched general community who are typically

377 much less physically active. Further, comparisons of the decade age groups also indicated that

378 the majority of these characteristics were well maintained from middle to older age in the

379 Masters athletes. Such data supports the promotion of a lifespan physical activity and sport

380 public health message, with such participation having a range of physical, social and economic

381 benefits for the individual and the wider community. Future research in this area should look to

382 include a wider range of health and functional outcomes and utilize longitudinal case-control

383 research designs to better compare the age-related changes in these outcomes between Masters

384 Athletes and their less active age-matched peers. 
386 ACKNOWLEDGEMENTS

387 We would like to thank the organisers and athletes of the 2014 Pan Pacific Masters Games for

388 their assistance in conducting the study. We would also like to thank the Bachelor of Exercise 389 and Sport Science students from the Faculty of Sport and Exercise Science, Bond University 390 who helped to collect the data.

391

392

393

394

395

396 
397

398

399

400

401

402

403

404

405

406

407

408

409

410

411

412

413

414

415

416

417

418

419

\section{References:}

Abellan van Kan G, Rolland Y, Andrieu S, Bauer J, Beauchet O, Bonnefoy M, Cesari M, Donini LM, Gillette Guyonnet S, Inzitari M, Nourhashemi F, Onder G, Ritz P, Salva A, Visser M, and Vellas B. 2009. Gait speed at usual pace as a predictor of adverse outcomes in community-dwelling older people an International Academy on Nutrition and Aging (IANA) Task Force. Journal of Nutrition, Health and Aging 13:881-889.

Australian Bureau of Statistics. 2012. Australian Health Survey: First Results, 2011-12, http://www.abs.gov.au/AUSSTATS/abs@.nsf/DetailsPage/4364.0.55.001201112? OpenDocument.

Australian Institute of Health and Welfare. 2014. Australia's Health 2014. Australia's health series no 14 Cat no AUS 178. Canberra: Australian Institute of Health and Welfare.

Avery FD, Lyman OB, and Congregational Church (Columbia Conn. : Town). 1867. The 150th anniversary of the organization of the Congregational Church in Columbia, Conn., October 24th, 1866 : historical papers, addresses : with appendix. Hartford: Printed by Case, Lockwood \& Co.

Bai HJ, Sun JQ, Chen M, Xu DF, Xie H, Yu ZW, Bao ZJ, Chen J, Pan YR, Lu DJ, and Cheng S. 2016. Age-related decline in skeletal muscle mass and function among elderly men and women in Shanghai, China: a cross sectional study. Asia Pacific Journal of Clinical Nutrition 25:326-332. 10.6133/apjen.2016.25.2.14

Borges N, Reaburn P, Driller M, and Argus C. 2016. Age-Related Changes in Performance and Recovery Kinetics in Masters Athletes: A Narrative Review. Journal of Aging \& Physical Activity 24:149-157. 10.1123/japa.2015-0021

Climstein M, Walsh J, Debeliso M, Heazlewood T, Sevene T, and Adams K. in press. 
Cardiovascular risk profiles of world masters games participants. Journal of Sports Medicine and Physical Fitness.

422 Cruz-Jentoft AJ, Baeyens JP, Bauer JM, Boirie Y, Cederholm T, Landi F, Martin FC, Michel JP,

423 Rolland Y, Schneider SM, Topinkova E, and Vandewoude M. 2010a. Sarcopenia: European consensus on definition and diagnosis: report of the European Working Group on Sarcopenia in Older People. Age Ageing 39:412-423.

Cruz-Jentoft AJ, Baeyens JP, Bauer JM, Boirie Y, Cederholm T, Landi F, Martin FC, Michel JP, Rolland Y, Schneider SM, Topinkova E, Vandewoude M, Zamboni M, and European Working Group on Sarcopenia in Older P. 2010b. Sarcopenia: European consensus on definition and diagnosis: Report of the European Working Group on Sarcopenia in Older People. Age \& Ageing 39:412-423. 10.1093/ageing/afq034

Cruz-Jentoft AJ, Landi F, Schneider SM, Zuniga C, Arai H, Boirie Y, Chen LK, Fielding RA, Martin FC, Michel JP, Sieber C, Stout JR, Studenski SA, Vellas B, Woo J, Zamboni M, and Cederholm T. 2014. Prevalence of and interventions for sarcopenia in ageing adults:

Geard D, Reaburn P, Rebar A, and Dionigi R. in press. Masters Athletes: Exemplars of 442 a systematic review. Report of the International Sarcopenia Initiative (EWGSOP and IWGS). Age and Ageing 43:748-759. 10.1093/ageing/afu115

Fien S, Henwood T, Climstein M, and Keogh JWL. 2016. Feasibility and benefits of groupbased exercise in residential aged care adults: a pilot study for the GrACE programme. PeerJ 4:e2018. 10.7717/peerj.2018

Gacesa J. 2017. Anaerobic Strength and Power in Master Athletes. Sports Medicine International Open 01:E30-E36. 10.1055/s-0042-123695 successful aging? Journal of Aging \& Physical Activity. 10.1123/japa.2016-0050 
443 Julien D, Gauvin L, Richard L, Kestens Y, and Payette H. 2013. The role of social participation

444

445

446

447

448

449

450

451

452

453

454

455

456

457

458

459

460

461

462

463

464

465

and walking in depression among older adults: results from the VoisiNuAge study. Canadian Journal on Aging 32:1-12. 10.1017/s071498081300007x

Kanamori S, Kai Y, Kondo K, Hirai H, Ichida Y, Suzuki K, and Kawachi I. 2012. Participation in sports organizations and the prevention of functional disability in older Japanese: the AGES Cohort Study. PLoS One 7:e51061. 10.1371/journal.pone.0051061

Kelly JS, and Metcalfe J. 2012. Validity and Reliability of Body Composition Analysis Using the Tanita BC418-MA. Journal of Exercise Physiology Online 15:74-83.

Keogh JW, Senior H, Beller EM, and Henwood T. 2015. Prevalence and risk factors for low habitual walking speed in nursing home residents: an observational study. Archives of Physical Medicine and Rehabilitation 96:1993-1999. 10.1016/j.apmr.2015.06.021

Kressig RW, Gregor RJ, Oliver A, Waddell D, Smith W, O-Grady M, Curns AT, Kutner M, and Wolf SL. 2004. Temporal and spatial features of gait in older adults transitioning to frailty. Gait Posture 20:30-35.

Lavie CJ, Milani RV, and Ventura HO. 2009. Obesity and cardiovascular disease: risk factor, paradox, and impact of weight loss. Journal of the American College of Cardiology 53:1925-1932. 10.1016/j.jacc.2008.12.068

Lepers R, and Stapley PJ. 2016. Master Athletes Are Extending the Limits of Human Endurance. Frontiers in Physiology 7:613. 10.3389/fphys.2016.00613

Manini TM, and Pahor M. 2009. Physical activity and maintaining physical function in older adults. British Journal of Sports Medicine 43:28-31. 10.1136/bjsm.2008.053736

McDonough AL, Batavia M, Chen FC, Kwon S, and Ziai J. 2001. The validity and reliability of the GAITRite system's measurements: a preliminary evaluation. Arch Phys Med Rehabil 
466

467

468

469

470

471

472

473

474

475

476

477

478

479

480

481

482

483

484

485

486

487

488

82:419-425. 10.1053/apmr.2001.19778

McKean KA, Manson NA, and Stanish WD. 2006. Musculoskeletal injury in the masters runners. Clinical Journal of Sport Medicine 16:149-154.

Olsen C, Pedersen, I., Bergland, A., Enders-Slegers, M. J., Joranson, N., Calogiuri, G., \& Ihlebaek, C. . 2016 Differences in quality of life in home-dwelling persons and nursing home residents with dementia - a cross-sectional study. . BMC Geriatrics 16. $10.1186 / \mathrm{s} 12877-016-0312-4$

Pantoja PD, De Villarreal ES, Brisswalter J, PeyrÉ-Tartaruga LA, and Morin J-B. 2016. Sprint acceleration mechanics in Masters Athletes. Medicine \& Science in Sports \& Exercise 48:2469-2476. 10.1249/MSS.0000000000001039

Pi-Sunyer X. 2009. The medical risks of obesity. Postgraduate Medicine 121:21-33. 10.3810/pgm.2009.11.2074

Power GA, Minozzo FC, Spendiff S, Filion ME, Konokhova Y, Purves-Smith MF, Pion C, Aubertin-Leheudre M, Morais JA, Herzog W, Hepple RT, Taivassalo T, and Rassier DE. 2016. Reduction in single muscle fiber rate of force development with aging is not attenuated in world class older masters athletes. American Journal of Physiology: Cell Physiology 310:C318-327. 10.1152/ajpcell.00289.2015

Pratley RE, Hagberg JM, Rogus EM, and Goldberg AP. 1995. Enhanced insulin sensitivity and lower waist-to-hip ratio in master athletes. American Journal of Physiology 268:E484490.

Ransdell LB, Vener J, and Huberty J. 2009. Masters athletes: an analysis of running, swimming and cycling performance by age and gender. Journal of Exercise Science \& Fitness 7:S61-73. 
489 Reijnierse EM, de Jong N, Trappenburg MC, Blauw GJ, Butler-Browne G, Gapeyeva H, Hogrel

490 JY, McPhee JS, Narici MV, Sipila S, Stenroth L, van Lummel RC, Pijnappels M,

491

492

493

494

495

496

497

498

499

500

501

502

503

504

505

506

507

508

509

Meskers CG, and Maier AB. 2017. Assessment of maximal handgrip strength: how many attempts are needed? Journal of Cachexia, Sarcopenia and Muscle. 10.1002/jcsm.12181

Senior HE, Henwood TR, Beller EM, Mitchell GK, and Keogh JWL. 2015. Prevalence and risk factors of sarcopenia among adults living in nursing homes. Maturitas 82:418-423

Walsh J, Climstein M, Heazlewood I, Burke S, Kettunen J, Adams K, and DeBeliso M. 2011. Variations in body mass index with age in Masters athletes (World Masters Games). Journal of the World Academy of Science, Engineering and Technology 7:1115-1119.

Walsh J, Climstein M, Heazlewood IT, Debeliso M, Adams KJ, Burke S, and Kettunen J. 2013 a. Body mass index of Masters basketball players. Medicina Sportiva 7:1700-1705.

Walsh J, Climstein M, Heazlewood IT, Kettunen J, Burke S, Debeliso M, and Adams KJ. 2013 b. Body mass index for athletes participating in swimming at the World Masters Games. Journal of Sports Medicine and Physical Fitness 53:162-168.

Wroblewski AP, Amati F, Smiley MA, Goodpaster B, and Wright V. 2011. Chronic exercise preserves lean muscle mass in masters athletes. Physician \& Sportsmedicine 39:172-178. $10.3810 / \mathrm{psm} .2011 .09 .1933$

Young BW, Weir PL, Starkes JL, and Medic N. 2008. Does lifelong training temper age-related decline in sport performance? Interpreting differences between cross-sectional and longitudinal data. Experimental Aging Research 34:27-48. 10.1080/03610730701761924 


\section{Table $\mathbf{1}$ (on next page)}

Anthropometric, functional, training and health characteristics of total sample.

All values are mean \pm SD except sarcopenic status whereby count is the number of individuals with sarcopenia in each category. ${ }^{\mathrm{a}}=$ significantly different to $50-59$ years old group; ${ }^{b}=$ significantly significant to $60-69$ years old group; ${ }^{c}=$ significantly significant to $70-79$ years old group. 
1 Table 1. Anthropometric, Functional, Training and Health Characteristics of Total Sample.

\begin{tabular}{|c|c|c|c|c|c|}
\hline & $\begin{array}{c}\text { 40-49 years } \\
(n=42)\end{array}$ & $\begin{array}{c}50-59 \text { years } \\
\quad(n=66)\end{array}$ & $\begin{array}{c}\text { 60-69 years } \\
(n=30)\end{array}$ & $\begin{array}{c}70-79 \text { years } \\
(n=18)\end{array}$ & $\begin{array}{c}\text { Total } \\
(n=156)\end{array}$ \\
\hline \multicolumn{6}{|c|}{ Anthropometric Characteristics } \\
\hline Height $(\mathrm{cm})$ & $172.6 \pm 8.4$ & $173.6 \pm 7.9^{b}$ & $167.9 \pm 11.0$ & $171.1 \pm 11.7$ & $171.9 \pm 9.3$ \\
\hline Mass (kg) & $76.6 \pm 14.4$ & $77.5 \pm 15.8$ & $73.3 \pm 13.7$ & $77.1 \pm 17.7$ & $76.4 \pm 15.2$ \\
\hline Fat $\%$ & $22.9 \pm 8.3$ & $22.2 \pm 9.1$ & $26.9 \pm 9.7$ & $27.1 \pm 10.3$ & $23.8 \pm 9.3$ \\
\hline Fat mass (kg) & $17.5 \pm 7.3$ & $17.6 \pm 9.5$ & $19.7 \pm 8.7$ & $21.2 \pm 10.1$ & $18.4 \pm 8.9$ \\
\hline FFM (kg) & $59.1 \pm 13.1$ & $59.8 \pm 11.3$ & $53.5 \pm 12.6$ & $55.8 \pm 13.7$ & $57.9 \pm 12.5$ \\
\hline BMI $\left(\mathrm{kg} / \mathrm{m}^{2}\right)$ & $25.5 \pm 3.5$ & $25.6 \pm 4.3$ & $25.9 \pm 4.7$ & $26.3 \pm 5.7$ & $25.7 \pm 4.3$ \\
\hline \multicolumn{6}{|l|}{ Status (Count) } \\
\hline \multicolumn{6}{|c|}{ Functional Characteristics } \\
\hline $\begin{array}{c}\text { Grip strength } \\
\text { (kg) }\end{array}$ & $\begin{array}{c}43.9 \pm 13.2 \\
b, c\end{array}$ & $\begin{array}{c}43.8 \pm 11.7 \\
b, c\end{array}$ & $35.1 \pm 12.4$ & $31.9 \pm 8.5$ & $40.8 \pm 12.7$ \\
\hline Gait speed (m/s) & $1.25 \pm 0.18$ & $1.28 \pm 0.21$ & $1.27 \pm 0.19$ & $1.26 \pm 0.22$ & $1.27 \pm 0.20$ \\
\hline \multicolumn{6}{|c|}{ Training and Health Characteristics } \\
\hline $\begin{array}{l}\text { Participation } \\
\text { (years) }\end{array}$ & $5.9 \pm 5.9 \mathrm{a}, \mathrm{c}$ & $10.4 \pm 8.5$ & $11.1 \pm 10.6$ & $15.8 \pm 10.5$ & $9.9 \pm 9.0$ \\
\hline Training (hours) & $6.0 \pm 3.7$ & $4.5 \pm 3.3$ & $4.3 \pm 3.9$ & $6.8 \pm 5.1$ & $5.1 \pm 3.8$ \\
\hline $\begin{array}{l}\text { Chronic diseases } \\
\text { (number) }\end{array}$ & $0.1 \pm 0.2^{b, c}$ & $0.2 \pm 0.6^{\mathrm{b}, \mathrm{c}}$ & $0.8 \pm 1$ & $1.0 \pm 1.0$ & $0.4 \pm 0.8$ \\
\hline $\begin{array}{l}\text { Prescribed } \\
\text { medications } \\
\text { (number) }\end{array}$ & $0.1 \pm 0.2^{b, c}$ & $0.2 \pm 0.7^{\mathrm{c}}$ & $0.6 \pm 1.0$ & $1.2 \pm 1.2$ & $0.4 \pm 0.8$ \\
\hline
\end{tabular}


6 


\section{Table 2 (on next page)}

Anthropometric, functional, training and health characteristics of male sample.

All values are mean \pm SD except sarcopenic status whereby count is the number of individuals with sarcopenia in each category. ${ }^{\mathrm{a}}=$ significantly different to $50-59$ years old group; ${ }^{\mathrm{b}}=$ significantly significant to $60-69$ years old group; ${ }^{c}=$ significantly significant to $70-79$ years old group. 
1 Table 2. Anthropometric, Functional, Training and Health Characteristics of Male Sample.

\begin{tabular}{cccccc}
\hline & $\begin{array}{c}40-49 \text { years } \\
(\mathrm{n}=19)\end{array}$ & $\begin{array}{c}50-59 \text { years } \\
(\mathrm{n}=39)\end{array}$ & $\begin{array}{c}60-69 \text { years } \\
(\mathrm{n}=11)\end{array}$ & $\begin{array}{c}70-79 \text { years } \\
(\mathrm{n}=9)\end{array}$ & $\begin{array}{c}\text { Total } \\
(\mathrm{n}=78)\end{array}$ \\
\hline Anthropometric Characteristics & & & & \\
Height (cm) & $180.1 \pm 6.2$ & $176.7 \pm 6.7$ & $177.2 \pm 12.6$ & $178.3 \pm 10.2$ & $177.8 \pm 8.0$ \\
Mass (kg) & $88.3 \pm 10.5$ & $83.7 \pm 15.7$ & $83.3 \pm 11.2$ & $87.5 \pm 12.7$ & $85.2 \pm 13.6$ \\
Fat \% & $18.2 \pm 7.0$ & $18.4 \pm 8.2$ & $20.3 \pm 6.4$ & $23.2 \pm 5.6$ & $19.2 \pm 7.5$ \\
Fat mass (kg) & $16.4 \pm 7.5$ & $16.4 \pm 10.6$ & $16.6 \pm 4.8$ & $20.6 \pm 7.4$ & $16.9 \pm 8.9$ \\
FFM (kg) & $71.9 \pm 7.7$ & $67.3 \pm 7.4$ & $66.7 \pm 11.6$ & $66.9 \pm 8.7$ & $68.3 \pm 8.4$ \\
BMI (kg/m ${ }^{2}$ ) & $27.2 \pm 3.1$ & $26.8 \pm 4.5$ & $26.6 \pm 3.2$ & $27.4 \pm 2.8$ & $26.9 \pm 3.8$ \\
Sarcopenic & 0 & 0 & 0 & 0 & 0 \\
Status (Count) & & & & &
\end{tabular}

Functional Characteristics

Grip strength $\quad 55.2 \pm 9.4^{\mathrm{b}, \mathrm{c}} \quad 51.3 \pm 8.5^{\mathrm{c}} \quad 45.6 \pm 14.0 \quad 37.5 \pm 5.9 \quad 49.9 \pm 10.7$ $(\mathrm{kg})$

Gait speed (m/s) $\quad 1.25 \pm 0.19 \quad 1.25 \pm 0.19 \quad 1.29 \pm 0.14 \quad 1.24 \pm 0.21 \quad 1.26 \pm 0.18$

Training and Health Characteristics

\begin{tabular}{|c|}
\hline Participation \\
\hline
\end{tabular}

$\begin{array}{lllll}\text { Training (hours) } \quad 6.6 \pm 4.2 & 4.1 \pm 3.6 & 5.3 \pm 4.3 & 7.2 \pm 6 & 5.2 \pm 4.3\end{array}$

$\begin{array}{llllll}\text { Chronic diseases } & 0.0 \pm 0.0^{\mathrm{b}, \mathrm{c}} & 0.1 \pm 0.3^{\mathrm{b}, \mathrm{c}} & 1.2 \pm 1.0 & 1.0 \pm 0.9 & 0.3 \pm 0.7\end{array}$ (number)

$\begin{array}{llllll}\text { Prescribed } & 0.1 \pm 0.2^{\mathrm{b}, \mathrm{c}} & 0.1 \pm 0.3^{\mathrm{b}, \mathrm{c}} & 0.9 \pm 1.2 & 1.1 \pm 0.9 & 0.3 \pm 0.7\end{array}$ medications (number)

2 All values are mean \pm SD except sarcopenic status whereby count is the number of individuals with

3 sarcopenia in each category. ${ }^{a}=$ significantly different to $50-59$ years old group; ${ }^{b}=$ significantly 
4 significant to 60-69 years old group; ${ }^{\mathrm{c}}=$ significantly significant to 70-79 years old group. 


\section{Table 3(on next page)}

Anthropometric, functional, training and health characteristics of female sample.

All values are mean \pm SD except sarcopenic status whereby count is the number of individuals with sarcopenia in each category. ${ }^{\mathrm{a}}=$ significantly different to $50-59$ years old group; ${ }^{b}=$ significantly significant to $60-69$ years old group; ${ }^{c}=$ significantly significant to $70-79$ years old group. 
1 Table 3. Anthropometric, Functional, Training and Health Characteristics of Female Sample.

\begin{tabular}{|c|c|c|c|c|c|}
\hline & $\begin{array}{c}40-49 \text { years } \\
(n=23)\end{array}$ & $\begin{array}{c}\text { 50-59 years } \\
\quad(n=27)\end{array}$ & $\begin{array}{c}\text { 60-69 years } \\
\quad(n=19)\end{array}$ & $\begin{array}{c}\text { 70-79 years } \\
(n=9)\end{array}$ & $\begin{array}{l}\text { Total } \\
(n=78)\end{array}$ \\
\hline \multicolumn{6}{|c|}{ Anthropometric Characteristics } \\
\hline Height $(\mathrm{cm})$ & $166.4 \pm 3.9$ & $169.1 \pm 7.1^{b}$ & $162.6 \pm 5$ & $164 \pm 8.6$ & $166.1 \pm 6.5$ \\
\hline Mass (kg) & $67.2 \pm 9.9$ & $68.6 \pm 11$ & $67.5 \pm 11.7$ & $66.6 \pm 16.1$ & $67.7 \pm 11.3$ \\
\hline Body Fat \% & $27.4 \pm 6.7$ & $27.7 \pm 7.5$ & $30.7 \pm 9.4$ & $31.0 \pm 12.6$ & $28.7 \pm 8.4$ \\
\hline Fat mass $(\mathrm{kg})$ & $18.9 \pm 7$ & $19.5 \pm 7.5$ & $21.6 \pm 10$ & $21.9 \pm 12.7$ & $20.1 \pm 8.6$ \\
\hline FFM (kg) & $48.3 \pm 4.3$ & $49 \pm 5.7$ & $45.9 \pm 3.8$ & $44.7 \pm 6.8$ & $47.6 \pm 5.2$ \\
\hline BMI $\left(\mathrm{kg} / \mathrm{m}^{2}\right)$ & $24.3 \pm 3.3$ & $24 \pm 3.7$ & $25.7 \pm 5.4$ & $25.2 \pm 7.6$ & $24.6 \pm 4.6$ \\
\hline \multicolumn{6}{|l|}{ Status (Count) } \\
\hline \multicolumn{6}{|c|}{ Functional Characteristics } \\
\hline $\begin{array}{c}\text { Grip strength } \\
(\mathrm{kg})\end{array}$ & $34.1 \pm 6.4^{\mathrm{b}, \mathrm{c}}$ & $33 \pm 5.3^{c}$ & $29.2 \pm 5.9$ & $26.4 \pm 7.0$ & $31.6 \pm 6.5$ \\
\hline Gait speed $(\mathrm{m} / \mathrm{s})$ & $1.24 \pm 0.17$ & $1.31 \pm 0.23$ & $1.26 \pm 0.20$ & $1.27 \pm 0.23$ & $1.27 \pm 0.21$ \\
\hline \multicolumn{6}{|c|}{ Training and Health Characteristics } \\
\hline $\begin{array}{l}\text { Participation } \\
\text { (years) }\end{array}$ & $5.7 \pm 6.0$ & $7.3 \pm 5.2$ & $9.4 \pm 10.2$ & $12.1 \pm 6.3$ & $7.9 \pm 7.2$ \\
\hline Training (hours) & $5.4 \pm 3.2$ & $5.2 \pm 2.8$ & $3.8 \pm 6.7$ & $6.4 \pm 4.4$ & $5.1 \pm 3.4$ \\
\hline $\begin{array}{l}\text { Chronic diseases } \\
\text { (number) }\end{array}$ & $0.1 \pm 0.3^{c}$ & $0.5 \pm 0.8$ & $0.6 \pm 1.1$ & $1.1 \pm 1.2$ & $0.5 \pm 0.9$ \\
\hline $\begin{array}{l}\text { Prescribed } \\
\text { medications } \\
\text { (number) }\end{array}$ & $0.1 \pm 0.3^{c}$ & $0.5 \pm 1.1$ & $0.5 \pm 0.9$ & $1.3 \pm 1.5$ & $0.5 \pm 1$ \\
\hline
\end{tabular}

2 All values are mean \pm SD except sarcopenic status whereby count is the number of individuals with

3 sarcopenia in each category. ${ }^{\mathrm{a}}=$ significantly different to $50-59$ years old group; ${ }^{\mathrm{b}}=$ significantly

4 significant to 60-69 years old group; ${ }^{\mathrm{c}}=$ significantly significant to $70-79$ years old group. 
Figure 1

Body Mass Index (BMI) classifications of overweight and obesity for the overall sample of Masters athletes as well as compared to Australian Bureau of Statistics (2012) data.

\section{BMI Classifications}

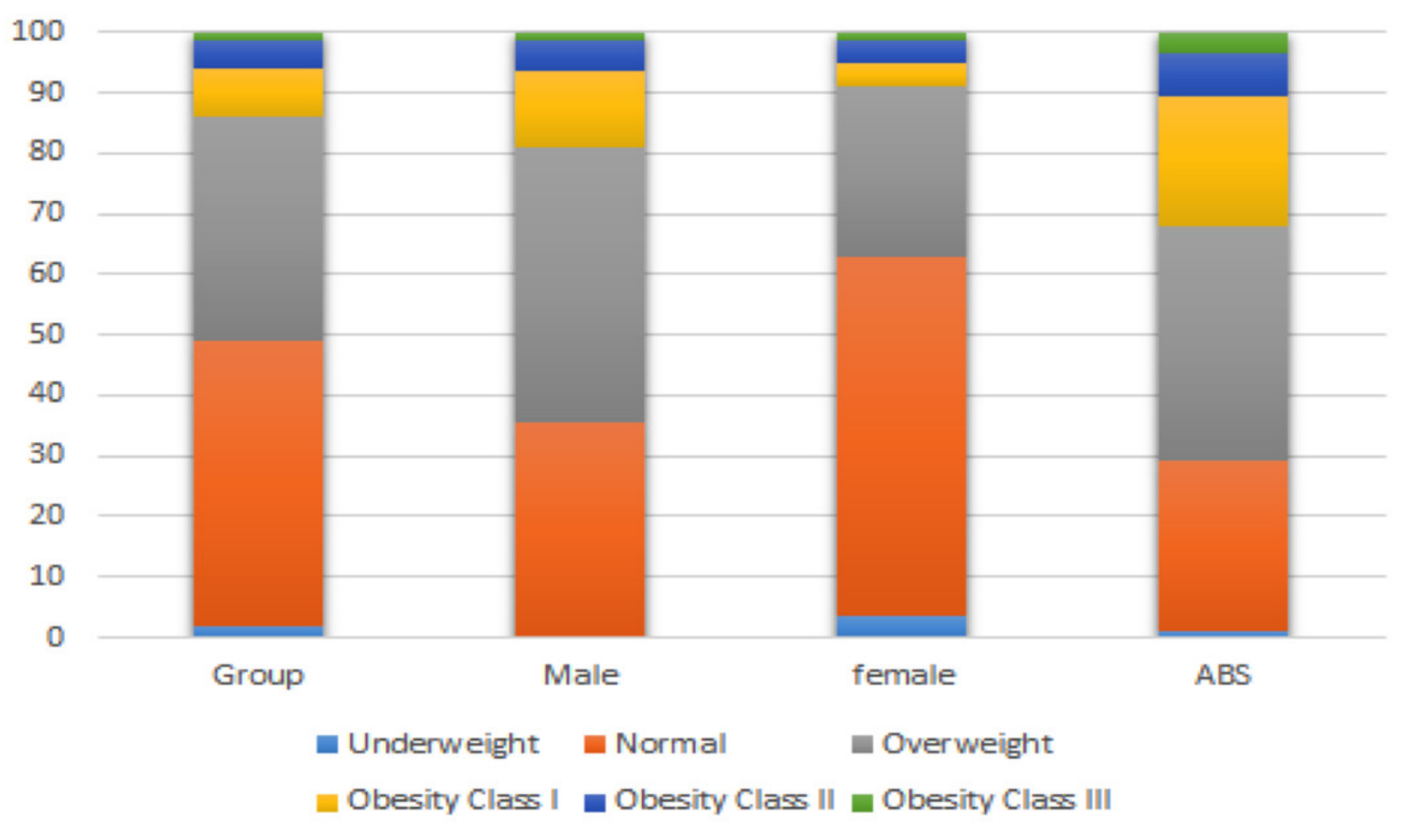


Figure 2

Proportion and total number of Masters athletes who were below the EWGSOP gait speed (A) and handgrip strength thresholds (B) for the male and female Masters athletes across the 10 year age groups.

Gait speed (A) and handgrip strength thresholds (B). 


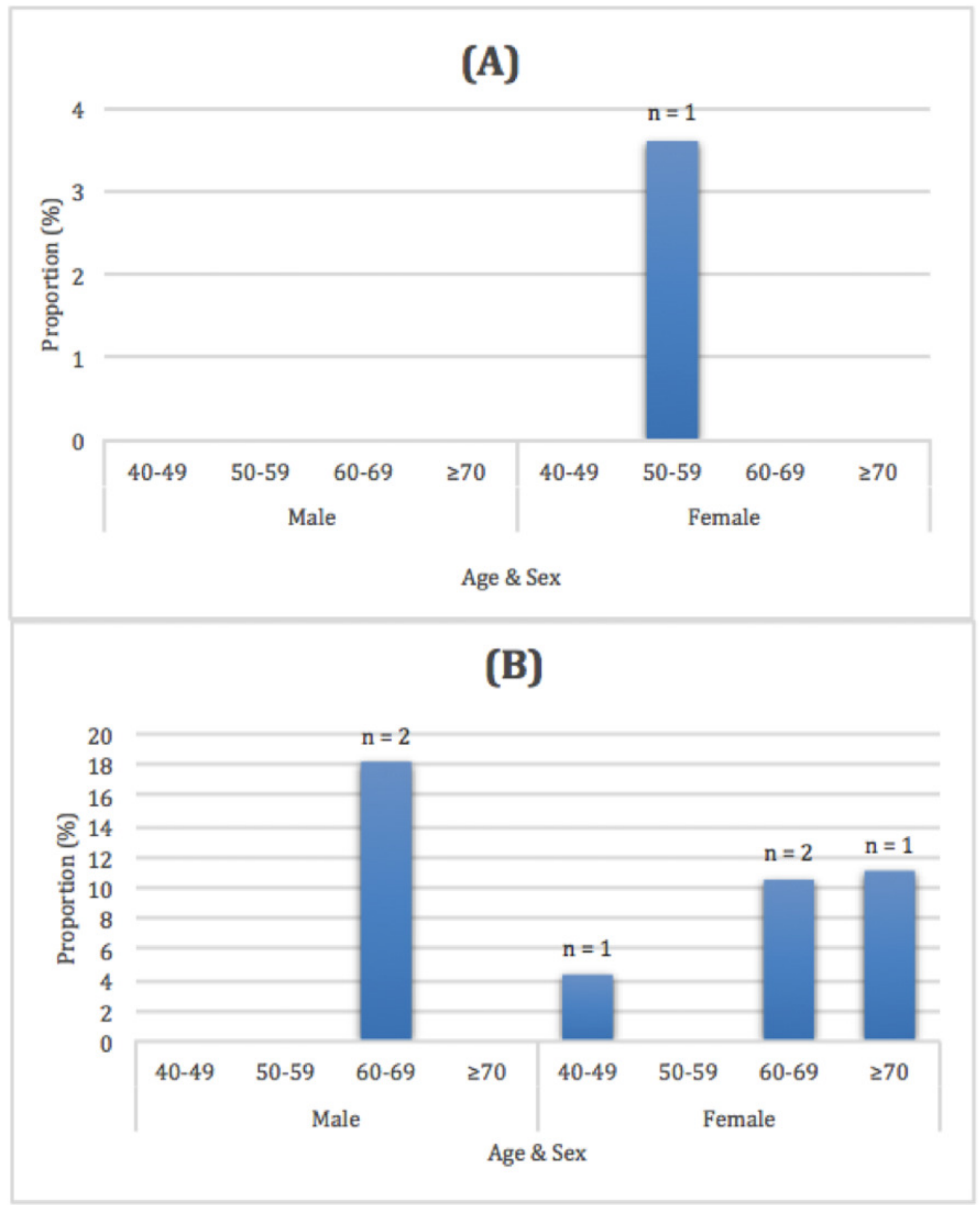

